Article

\title{
Flame Retardant Submicron Particles via Surfactant-Free RAFT Emulsion Polymerization of Styrene Derivatives Containing Phosphorous
}

\author{
Taeyoon Kim ${ }^{1}{ }^{\circledR}$, Joo-Hyun Song ${ }^{1,2}$, Jong-Ho Back ${ }^{1}$, Bongkuk Seo ${ }^{1}$, Choong-Sun Lim ${ }^{1}$, \\ Hyun-Jong Paik ${ }^{2, *}$ and Wonjoo Lee ${ }^{1, *}$ \\ 1 Center for Advanced Specialty Chemicals, Korea Research Institute of Chemical Technology, Ulsan 44412, \\ Korea; xodbs17@krict.re.kr (T.K.); joohyun@krict.re.kr (J.-H.S.); beak1231@krict.re.kr (J.-H.B.); \\ bksea@krict.re.kr (B.S.); chsunlim@krict.re.kr (C.-S.L.) \\ 2 Department of Polymer Science and Engineering, Pusan National University, Busan 46241, Korea \\ * Correspondence: hpaik@pusan.ac.kr (H.-J.P.); winston@krict.re.kr (W.L.)
}

Received: 31 March 2020; Accepted: 27 May 2020; Published: 29 May 2020

\begin{abstract}
The reversible addition-fragmentation chain transfer (RAFT) emulsion polymerization of diethyl-(4-vinylbenzyl) phosphate (DEVBP) was performed using PEG-TTC as a macro RAFT agent. PEG-TTC $\left(\mathrm{M}_{\mathrm{W}} 2000,4000\right)$ was synthesized by the esterification of poly (ethylene glycol) methyl ether with a carboxylic-terminated RAFT agent, composed a hydrophilic poly (ethylene glycol) (PEG) block and a hydrophobic dodecyl chain. The RAFT emulsion polymerization of DEVBP was well-controlled with a narrow molecular size distribution. Dynamic light scattering and confocal laser scanning microscopy were used to examine the PEG-b-PDVBP submicron particles, and the length of the PEG chain (hydrophilic block) was found to affect the particle size distribution and molecular weight distribution. The submicron particle size increased with increasing degree of polymerization $(35,65$, and 130$)$, and precipitation was observed at a high degree of polymerization (DP) using low molecular weight PEG-TTC (DP 130, A3). The flame retardant properties of the PEG-b-PDVBP were evaluated by thermogravimetric analysis (TGA) and micro cone calorimeter (MCC). In the combustion process, the residue of PEG-b-PDEVBP were above $500{ }^{\circ} \mathrm{C}$ was observed (A1 B3, $27 \sim 38 \%$ ), and flame retardant effect of PEG-b-PDEVBP submicron particles/PVA composite were confirmed by increasing range of temperature and decreasing total heat release with increasing contents of PEG-b-PDEVBP. The PEG-b-PDEVBP submicron particles can provide flame retardant properties to aqueous, dispersion and emulsion formed organic/polymer products.
\end{abstract}

Keywords: phosphorus; flame retardant; RAFT; emulsion polymerization; surfactant-free

\section{Introduction}

Phosphorus-based polymers have many applications, such as organic-metal complex [1], biominerals [2], proton exchange membrane materials [3]. In particular, phosphorous organic compounds and polymers have flame retardant properties to prevent fire, and minimize damage from fire, through the physical incorporation of fire retardant additives [4]. Fire retardant polymers generally contain elements, such as halogens, phosphorus, silicon, and boron. Although halogen-based flame retardants show good performance, they generate toxic and corrosive gases, such as $\mathrm{Cl}_{2}, \mathrm{HCl}$, $\mathrm{Br}_{2}, \mathrm{HBr}$, and HF. Phosphorus-based flame retardants have been evaluated as alternative halogen flame retardants [5]. Phosphorinated halogen-free retardant coatings can lead to a char or a protective coating that prevents oxygen transport toward the burning area resulting in the extinguishing of a fire [5]. On the other hand, the physical incorporation of low molecular phosphorus compounds has 
some problems, such as the requirement of additives and lack of compatibility with organic, polymeric materials [6]. Therefore, flame retardant additives are needed to form polymers, copolymers, and modify the chemical structure.

Over the past few decades, reversible deactivation radical polymerization (RDRP) methods, such as atom transfer polymerization (ATRP) [7], stable free radical polymerization (SFRP) [8], and reversible addition-fragmentation chain transfer (RAFT), have been developed [9]. These techniques can allow control of the molecular weight with narrow polydispersity, as well as various structure polymers, and polymer chain-like blocks, grafts, stars, and gradient copolymers. In particular, RAFT polymerization is a simple process because of its relatively mild reaction conditions, lack of metal catalysts, and a wide range of monomers [10]. Heterogeneous RAFT polymerization has advantages, both industrially and environmentally, such emulsion, miniemulsion, self-assembly, and surfactant-free polymerization [11]. Conventional emulsion/dispersion polymerization uses a surfactant to stabilize polymeric particles, and RAFT emulsion polymerization has also used surfactant [12]. The final polymer product, however, has adverse effects on the properties of the products, due to surfactant migration through the polymeric material, leading to degradation of their adhesive and mechanical properties. In addition, they also harm the environment [12]. RAFT polymerization can provide surfactant-free emulsion polymerization because of its living character [12]. Recently, surfactant-free RAFT emulsion polymerization was shown that the particle size and shape size can be controlled, and it was widely used in the biomedical field $[13,14]$.

Matyjaszewski et al. we dimethyl(1-ethoxycarbonyl)vinyl phosphate (C-O-PO- $\left.\left(\mathrm{OCH}_{3}\right)_{2}\right)$ [15], dimethyl (methacryloyloxymethyl) phosphonate (C-PO- $\left.(\mathrm{OR})_{2}, \mathrm{PO}_{3}\right)$ [16], with a narrow molecular weight distribution. Dong et al. reported the ATRP of diethyl-(4-vinylbenzyl) phosphonate using polypropylene macroinitiator $\left(\mathrm{PO}_{3}\right)$, and NMP of diethyl-(4-vinylbenzyl) phosphonate $\left(\mathrm{PO}_{3}\right)$ was reported $\left(\mathrm{PO}_{3}\right)[5,17]$. Poly (methacryloyloxy methyl phosphonic acid) were directly synthesized by RAFT polymerization using methacryloyloxymethyl phosphonic acid, and synthesized by RAFT polymerization using methacryloyloxymethyl dimethylphosphonate followed by conversion to poly(methacryloxymethylphosphonic acid). Poly(methacryloxymethylphosphonic acid) was used for emulsion RAFT polymerization as the hydrophilic macro-CTA [18,19].

In this study, PEG-b-P(diethyl-(4-vinylbenzyl) phosphate (DEVBP))-based submicron particles were prepared by the RAFT emulsion polymerization of DEVBP, which was used as a hydrophobic monomer, using a poly (ethylene glycol)-based chain transfer agents. DEVBP was $\mathrm{PO}_{4}$ based styrene derivatives, which has been so far used in the conversional radical polymerization [20,21], and which monomer was first used for RAFT and emulsion RAFT polymerization as the hydrophobic macro-CTA. Furthermore, $\mathrm{PO}_{4}$-functionalized compounds/polymers show a good performance for flame retardant compared with $-\mathrm{PO}_{1},-\mathrm{PO}_{2},-\mathrm{PO}_{3}[22,23]$. Characterization of PEG-b-PDEVBPs were confirmed by ${ }^{1} \mathrm{H}$ and ${ }^{31} \mathrm{P}$ NMR, gel permeation chromatography (GPC) and PEG-b-PDEVBP submicron particles were observed by dynamic light scattering (DLS), confocal laser scanning microscope (CLSM). Flame-retardant properties of PEG-b-PDEVBP were performed by TGA, micro cone calorimeter (MCC). The synthesis of PEG-b-PDEVBP is illustrated below (Figure 1).

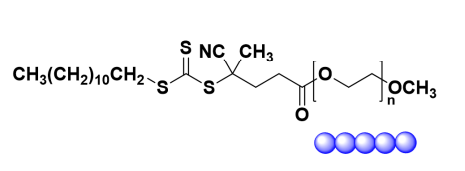

PEG-TTC

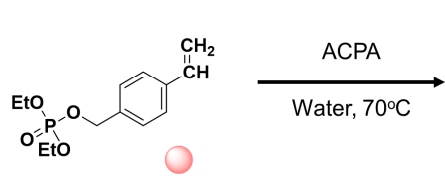

DEVBP

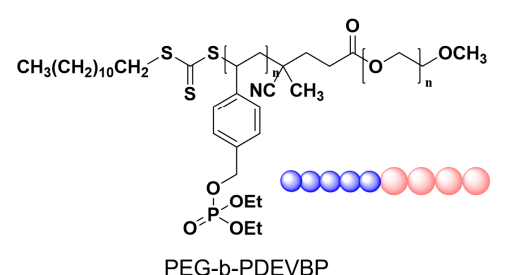

PEG-b-PDEVBP

Figure 1. Synthesis of PEG-b-PDVBP. 


\section{Materials and Methods}

\subsection{Materials}

4-vinylbenzyl chloride was purchased from Tokyo Chemical Industry Co., Ltd. (Tokyo, Japan) and dried by distillation prior to use. Diehtyl chlorophosphate was purchased from Tokyo Chemical Industry Co., Ltd. and used without further purification. 4,4'-azobis-4-cyanopentanoic acid (ACPA) was purchased from Wako Pure Chemical Co., Ltd. (Osaka, Japan) and dried by vacuum oven at room temperature before to use. Methoxy poly(ethylene glycol) (mPEG), 4-Dimethylaminopyridine (DMAP) and $\mathrm{N}, \mathrm{N}^{\prime}$-dicyclohexylcarbodiimide (DCC) were purchased from Alfa Aesar Co. (Waltham, MA, USA) Dichloromethane (DCM), dimethyl sulfoxide (DMSO) were purchased from Daejung Chemical \& Metal Co. (Siheung, Korea) and purified by distillation over $\mathrm{CaH}_{2}$. 4-Cyano-4-[(dodecylsulfanylthiocarbonyl)sulfanyl]pentanoic acid was synthesized by the reaction procedure according to the similar method reported elsewhere [24]. All other chemicals were used without further purification.

\subsection{Characterization}

${ }^{1} \mathrm{H}$ NMR and ${ }^{31} \mathrm{P}$ NMR spectra were recorded in $\mathrm{CDCl}_{3}$ on Bruker $300 \mathrm{Mhz}$ spectrometer. FT-IR spectra were obtained at a resolution of $4 \mathrm{~cm}^{-1}$ with ThermoFisher Nicolet 6700 spectrometer (Waltham, MA, USA) in the wavenumber rage of $4000 \sim 400 \mathrm{~cm}^{-1}$. The powder samples were incorporated into $\mathrm{KBr}$ pellets and IR measurements were performed. Thermal degradation was examined using a TA Q500 thermogravimetric analyzer (TGA) with heating rate of $10^{\circ} \mathrm{C} / \mathrm{min}$ under nitrogen atmosphere and samples were dried by the lyophilization. The heat resistance was studied with pyrolysis combustion flow calorimetry (PCFC, Fire Testing Technology Limited, West Sussex, UK) with the ASTM D7309 method. The samples were prepared by the mixing $10 \mathrm{wt} \%$ PVA solution with PEG-b-PDEVBP emulsion followed by the lyophilization of the mixture and then loaded in the instrument is heated at a rate of $1 \mathrm{C} / \mathrm{s}$ from 100 to $750{ }^{\circ} \mathrm{C}$ to obtain heat release rate (HRR) and total heat release (THR). Molecular weight and polydispersity were determined by (GPC), conducted with a Agilent 1260 isopump and Agilent 1260 differential refractometer using Agilent columns (Santa Clara, CA, USA) ( $2 \times$ PLgel $5 \mu \mathrm{m}$ MIXED-D, $7.5 \times 300 \mathrm{~mm}$ ) in THF as an eluent at $40{ }^{\circ} \mathrm{C}$ and at a flow rate of $1 \mathrm{~mL} / \mathrm{min}$. Linear polystyrene standards were used for calibration. Particles size measurement was performed on Malvern Nano-ZS90 (Malvern, UK). Multi-photon confocal microscopy images were acquired using a ZEISS LSM 780 (Oberkochen, Germany) configuration 16 NLO microscope with Nile red as fluorescent agent. To obtain the submicron particles stained with Nile red, DEVBP containing $0.1 \mathrm{wt} \%$ Nile red was used for RAFT emulsion polymerization.

\subsection{Synthesis of 4-Vinylbenzyl Alcohol (VBA)}

4-vinylbenzyl alcohol was synthesized as described before [25]. 4-vinylbenyl chloride ( $30.5 \mathrm{~g}$, $0.2 \mathrm{~mol})$, potassium acetate $(25 \mathrm{~g}, 0.25 \mathrm{~mol}), 0.05 \mathrm{~g}$ of t-butylcatechol were add in 3 neck round flask and dissolved in DMSO 200mL. The reaction mixture was stirred $20 \mathrm{~h}$ at $40^{\circ} \mathrm{C}$ under nitrogen. After reaction, $400 \mathrm{~mL}$ ether was added in the reaction mixture and then washed with distilled water and dried over $\mathrm{Na}_{2} \mathrm{SO}_{4}$. Colorless liqud 4-vinylbenzyl acetate was obtained. The obtained 4-vinylbenzyl acetate was hydrolyzed with a mixture of ethanol and potassium for $10 \mathrm{~h}$ at $50{ }^{\circ} \mathrm{C}$ under nitrogen. The product was wahsed with ether and water followed by dried over anhydrous $\mathrm{Na}_{2} \mathrm{SO}_{4}$.

\subsection{Synthesis of Diethyl 4-Vinylphenyl Phosphate (DEVBP)}

Diethyl 4-vinylphenyl phosphate was synthesized as discribed previously [20,25]. VBA and pyridine added a three necked round bottom flask, supplied with a dropping funnel and dissoved in dichlromethane, and then the reactin mixture cooled at $0{ }^{\circ} \mathrm{C}$ in an ice bath. Diethyl chlorophosphate dissolved in dicrhloromethane was dropwised in the reaction mixture and was sttired for $24 \mathrm{~h}$ at ambient temperature. After the reaction, pyridine. $\mathrm{HCl}$ was filtered follwed by filtrate was wished with 
distilled water 3 times. The organic layer dried with $\mathrm{Na}_{2} \mathrm{SO}_{4}$. Color less liquid product was obtained after dirchloromethane was evaporated.

\subsection{Synthesis of PEG-TTC (macro-CTA)}

PEG-TTC was synthesized by the reaction procedure according to the similar method reported elsewhere [26]. Typical procedure for the synthesis of PEG-TTC, MPEG and DMAP dissoved in $50 \mathrm{~mL}$ dichlromethane $250 \mathrm{~mL}$ in 3 neck flask. DCC in $40 \mathrm{~mL}$ of dichloromethane was dropwised in the reaction mixture for $1 \mathrm{~h}$ under nitrogen atmosphere and the reaction mixture was sttirred $120 \mathrm{~h}$. After reaction, pricipitated dicyclohexylurea was removed by filteration and the filtrate was pricipitated in cold ehtyl ethyl ether. The pricipitated product was dried in vacuum oven at ambient temperature for $24 \mathrm{~h}$ and sligtly yellow powder was obtained (See Figure 3).

\subsection{RAFT Emulsion Polymerization of Diethyl 4-Vinylphenyl Phosphate (DEVBP)}

PEG-TTC 4k (0.27 g, $0.060 \mathrm{mmol})$, ACPA (0.012 g, $0.042 \mathrm{mmol})$ were added to a $100 \mathrm{~mL}$ schlenk flask and dissolved in water. DEVBP $(1.06 \mathrm{~g}, 3.94 \mathrm{mmol})$ was added to the reaction mixture and dispersed. An aqueous stock solution of neutralized ACPA by $\mathrm{NaHCO}_{3}$ ( 3.5 molar equivalents with respect to ACPA) was prepared and added. Freeze-pump-thaw cycles were performed 3 times toremove oxygen. After the flask was backfilled with nitrogen, the polymerization was carried out at $70{ }^{\circ} \mathrm{C}$ for $6 \mathrm{~h}$. Adequate samples were periodically withdrawn from the reactor analyzed by by ${ }^{1} \mathrm{H}$ NMR to evaluate polymerization kinetics, conversion was calculated by the comparsion vinyl peak with methylene peaks of DEVBP.

\section{Results and Discussion}

The submicron particle size and distribution were characterized, and the flame retardant properties were investigated. PEG-TTC was synthesized by reacting PEG with CPD-TTC and RAFT emulsion polymerization of DEVBP with PEG-TTC (Figure 1). DEVBP was synthesized using a similar method to that reported elsewhere $[20,25]$, and its structure was confirmed by ${ }^{1} \mathrm{H}$ and ${ }^{31} \mathrm{P}$ nuclear magnetic resonance (NMR) spectra (Figure 2). In ${ }^{1} \mathrm{H}$ NMR spectrum of 4-vinylbenzyl acetate (Figure 2), $\omega$-methylene proton $\left(-\mathrm{CH}_{2}-\mathrm{Cl}\right)$ was shifted 4.79 to $5.08 \mathrm{ppm}$ with the appearance of methyl $\left(-\mathrm{CH}_{3}-\right)$ at $2.07 \mathrm{ppm}$ by the reacting 4-vinylbenyl chloride with potassium acetate. The VBA was synthesized by depreotection reaction, and confirmed by the shifting methylene proton $\left(-\mathrm{CH}_{2}-\mathrm{C}-\mathrm{O}\right)$ of 4-vinylbenzyl acetate at $5.08 \mathrm{ppm}$ to $4.48 \mathrm{ppm}$. Finally, DEVBP, styrene derivatives containing phosphorus, were obtained by the esterification of VBA with diethyl chlorophosphate. In ${ }^{1} \mathrm{H}$ NMR and ${ }^{31} \mathrm{P}$ NMR, DEVBP were identified by the appearance of methylene and methyl proton at 4.03, $1.23 \mathrm{ppm}$ corresponding to diethyl chlorophosphate (-P-O-CH $\left.-\mathrm{CH}_{2}-\mathrm{CH}_{3}\right)$ and the shifting phosphorus peak from -0.98 to $4.25 \mathrm{ppm}$. 


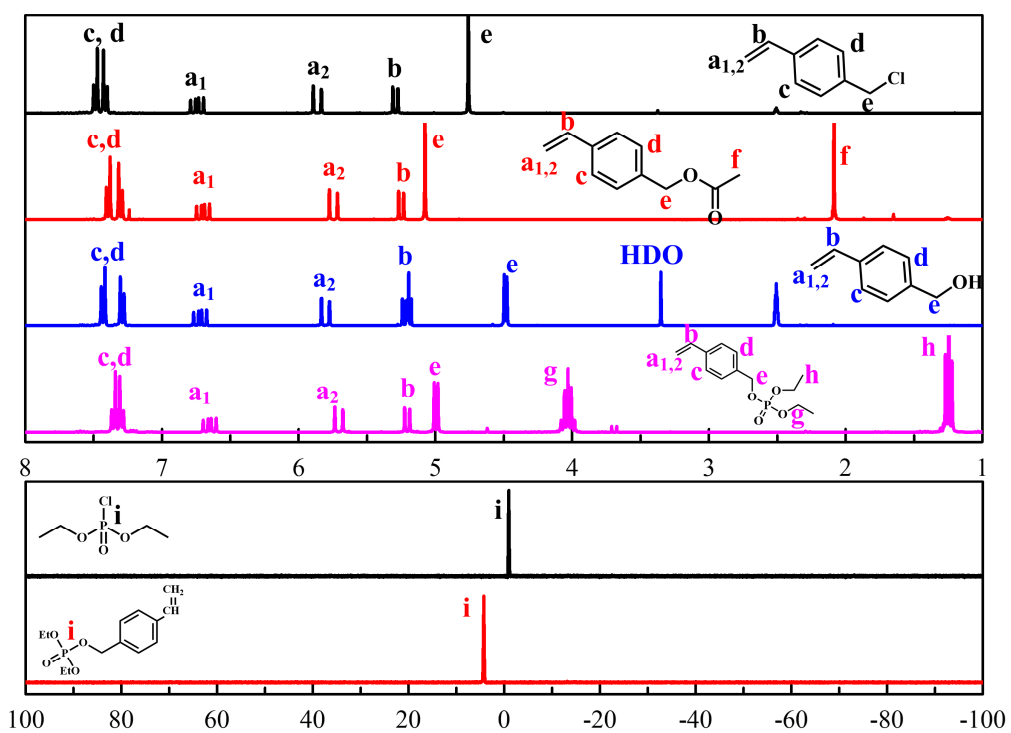

Figure 2. ${ }^{1} \mathrm{H}$ (4-vinylbenyl chloride, 4-vinylbenzyl acetate, 4-vinylbenzyl alcohol, diethyl 4-vinylphenyl phosphate) and 31P NMR spectra (diethyl chlorophosphate, diethyl 4-vinylphenyl phosphate).

A PEG-based macro RAFT agent have used for the emulsion RAFT polymerization of styrene [27], methyl methacrylate [28], butyl acrylate [26,28]. In previously, polymerization of styrene was very slow and low conversion in the presence of a PEG based dithiobenzoate macro RAFT agent [26,27]. On the other hand, a trithiocarbonate -based macro-RAFT agent, which was synthesized by reacting mPEG with 2-(dodecylthiocarbonothioylthio)-2-methylpropanoic acid), was used successfully as both a stabilizer and a reversible chain transfer agent in the ab initio batch emulsion polymerization of styrene, n-butyl acrylate, and methyl methacrylate, and the stable latexes were obtained [26-28]. The synthesized PEG-TTC $(2 \mathrm{k}, 4 \mathrm{k})$ were confirmed by the shift in the methylene group $\left(-\mathrm{CH}_{2}-\mathrm{C}-\right)$ of TTC at 2.75 to $4.25 \mathrm{ppm}$ in the ${ }^{1} \mathrm{H}$ NMR spectra (Figure 3a), as well as by the disappearance of a hydroxyl peak at $3000 \sim 3500 \mathrm{~cm}^{-1}$, and the appearance of a carbonyl peak at $1750 \mathrm{~cm}^{-1}$ in the FTIR spectra (Figure $3 b$ ). In gel permeation chromatography (GPC), the molecular weight of PEG-TTC was increased slightly after esterification with TTC (Figure 3c).

Functionality of TTC was above $92 \%$, as determined by comparing the integration of methyl protons $\left(\mathrm{CH}_{3}-\mathrm{CH}_{2}-\right)$ of TTC at $0.85 \mathrm{ppm}$ with methylene protons $\left(-\mathrm{CH}_{2}-\mathrm{CH}_{2}-\mathrm{O}-\right)$ of mPEG at $4.25 \mathrm{ppm}$. RAFT emulsion polymerization of DEVBP was conducted using PEG-TTC as an amphiphilic chain transfer agent and 4,4'-azobis(4-cyanopentanoic acid) (ACPA) as an initiator at $70{ }^{\circ} \mathrm{C}$ (Table 1 ). The copolymerization of diethyl-(4-vinylbenzyl) phosphate (DEVBP) $\left(-\mathrm{C}-\mathrm{O}-\mathrm{PO}-\left(\mathrm{OC}_{2} \mathrm{H}_{5}\right)_{2}\right)$ was performed by free radical polymerization $[21,25]$ and RAFT polymerization. In the current study, a phosphorus- containing styrene-derivative monomer (DEVBP) was first synthesized by RAFT emulsion polymerization and used as the hydrophobic moiety. The PEG-based trithiocarbonate macro RAFT agent consisted of poly (ethylene glycol) (hydrophilic moiety) and dodecyl aliphatic hydrocarbon chain (hydrophobic moiety). In the RAFT emulsion polymerization of DEVBP, PDVBP with a controlled molecular weight and narrow molecular weight distribution was synthesized within $6 \mathrm{~h}(83 \%<=$ conversion) (Figure 4). The molecular weights of PEG-b-PDVBP increased linearly with increasing conversion, which is the supporting evidence for controlled polymerization (Figure 4). No induction period for the homopolymerization for DEVBP was observed (Figure 4). However, it was shown that the tailing to low molecular weight, and the molecular weight of all polymers (Figure 5, A1-B3) was smaller in GPC than the actual molecular weight calculated by ${ }^{1} \mathrm{H}$ NMR spectroscopy (Table 1). In a previous paper, the polymerization of styrene, using PEG-TTC tailing, was not observed at high monomer conversion, and symmetrical curve was shown in GPC [26]. The hydrodynamic volume of PEG-b-PDEVBP series, a polymer of DEVBP derived from styrene, were very small compared with polystyrene standard. A strong intermolecular interaction occurred 
between the phosphate moieties of PEG-b-PDEVBP, leading to tailing toward low molecular weight (Figure 4). The polymerization behavior of DEVBP differed according to the molecular weight of PEG-TTC (2k, 4k). In cases of using PEG-TTC 2k, PDVBP was obtained with a relatively narrow molar mass distribution $\left(\mathrm{M}_{\mathrm{n}} / \mathrm{M}_{\mathrm{W}}: 1.07 \sim 1.08\right)$ than PEG-TTC4k $\left(\mathrm{M}_{\mathrm{n}} / \mathrm{M}_{\mathrm{w}}: 1.15 \sim 1.20\right)$ (Table 1, Figure 5). The vinyl peaks at 5.7,6.7 ppm, and the polymer backbone at $1 \sim 2 \mathrm{ppm}$ disappeared and appeared, respectively, in the ${ }^{1} \mathrm{H}$ NMR spectra (Figures 6 and 7) after polymerization. In addition, phosphorus peaks were also observed in the ${ }^{31} \mathrm{P}$ NMR spectra (Figures 6 and 7). The PEG-b-PDVBP particles were obtained by emulsion RAFT polymerization (Figures 8 and 9). Particles size increased with increasing molecular weight in emulsion RAFT polymerization previously [29], the PDVBP particle size also increased with increasing target molecular weight (z- average size $216 \sim 1056 \mathrm{~nm}$ ). On the other hand, the particle size distribution increased by the degree of polymerization (DP). The particle size of A2 (DP 65) was larger, and the particle distribution was much broader than A1 (DP 32). Furthermore, the precipitation of particles was observed. Short chain PEG 2K could not stabilize PDVBP with a high DP (Figure 6). In contrast, in a series of experiments (B1 B3), PEG -TTC 4k was used as an amphiphilic RAFT agent. All of the PDVBP particles were obtained with a stable and narrow size distribution (194 $576 \mathrm{~nm}$ ). The PEG-TTC 4k-based particles were smaller than the PEG-TTC 2K-based particles, PEG-TTC 2K-based particles aggregated because of their short hydrophilic chain. Phosphorus compounds can provide excellent thermal stability and show enhanced char formation during the combustion process.
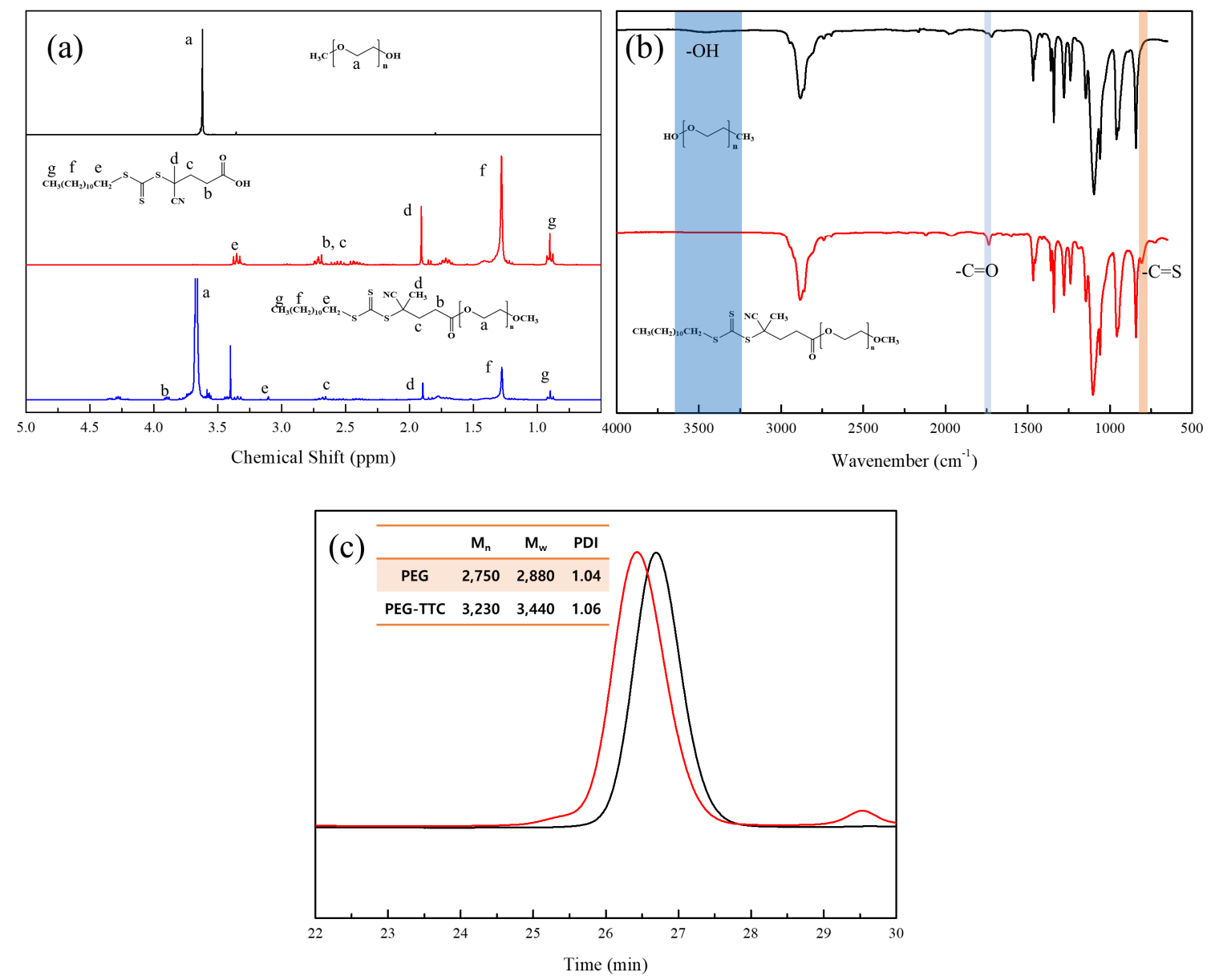

Figure 3. Macro RAFT agent (PEG-TTC) of (a) ${ }^{1} \mathrm{H}$ NMR spectra, (b) FTIR spectra, (c) GPC measurements. 
Table 1. Polymerization and colloidal properties of polymer particles synthesized via the RAFT Emulsion homopolymerization of DEVBP.

\begin{tabular}{|c|c|c|c|c|c|c|c|c|c|c|}
\hline \multirow[b]{2}{*}{ Entry } & \multirow{2}{*}{$\begin{array}{c}\text { Monomer } \\
\text { wt. \% }\end{array}$} & \multirow{2}{*}{$\begin{array}{c}\text { Mn } \\
\text { (PEG) }\end{array}$} & \multirow[b]{2}{*}[\mathrm{DEVBP}]{$_{0} /[\mathrm{PEG}-\mathrm{TTC}]_{0}$} & \multirow{2}{*}{$\begin{array}{c}P_{\text {theory }} \\
\%\end{array}$} & \multirow{2}{*}{$\begin{array}{c}\text { Conversion } \\
\%\end{array}$} & \multicolumn{3}{|c|}{ Molecular Weight } & \multirow{2}{*}{ 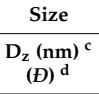 } & \multirow{2}{*}{$\begin{array}{c}\text { Residual Weight at } \\
500^{\circ} \mathrm{C}(\%) \\
\text { TGA Analysis }\end{array}$} \\
\hline & & & & & & Theory ${ }^{b}$ & $\begin{array}{l}\text { GPC } \\
(\mathrm{Mw} / \mathrm{Mn})\end{array}$ & ${ }^{1} \mathrm{H}$ NMR & & \\
\hline A1 & 5 & $2 \mathrm{~K}$ & 32 & 9.0 & 89 & 10,100 & $\begin{array}{l}5200 \\
(1.08)\end{array}$ & 9800 & $\begin{array}{c}216 \\
(0.22)\end{array}$ & 27.1 \\
\hline $\mathrm{A} 2$ & 9 & $2 \mathrm{~K}$ & 65 & 10.1 & 85 & 17,300 & $\begin{array}{c}9400 \\
(1.08)\end{array}$ & 16,800 & $\begin{array}{l}1056 \\
(0.68)\end{array}$ & 33 \\
\hline A3 & 16 & $2 \mathrm{~K}$ & 130 & 10.7 & 92 & 31,500 & $\begin{array}{l}16,100 \\
(1.07)\end{array}$ & 34,200 & - & 37.8 \\
\hline B1 & 5 & $4 \mathrm{~K}$ & 32 & 7.6 & 91 & 12,300 & $\begin{array}{c}6700 \\
(1.20)\end{array}$ & 12,200 & $\begin{array}{c}194 \\
(0.22)\end{array}$ & 34.5 \\
\hline B2 & 9 & $4 \mathrm{~K}$ & 65 & 9.1 & 82 & 18,800 & $\begin{array}{l}11,000 \\
(1.35)\end{array}$ & 18,100 & $\begin{array}{c}302 \\
(0.10)\end{array}$ & 37.1 \\
\hline B3 & 16 & $4 \mathrm{~K}$ & 130 & 10.2 & 87 & 35,000 & $\begin{array}{l}14,100 \\
(1.17)\end{array}$ & 33,200 & $\begin{array}{c}576 \\
(0.20)\end{array}$ & 38.1 \\
\hline
\end{tabular}

Reaction condition: $[\text { PEG-TTC }]_{0}=5.5 \mathrm{mmol} / \mathrm{L},[\mathrm{ACPA}]=1.65 \mathrm{mmol} / \mathrm{L}$, temperature $=70{ }^{\circ} \mathrm{C}$, time $=6 \mathrm{~h}$. ACPA as used initiator was neutralized by 3 mol equiv of $\mathrm{NaHCO}_{3}$. ${ }^{\text {a }}$ Monomer conversion was determined by ${ }^{1} \mathrm{H}$ NMR. ${ }^{\mathrm{b}}$ Theoretical number-average molar weight at the experimentally determined conversion; M.W PEG-TTC $[\mathrm{DEVBP}]_{0} /[\mathrm{PEO}-\mathrm{TTC}]_{0}{ }^{\mathrm{c}} \mathrm{D}_{\mathrm{z}}$ is the average particle diameter from dynamic light scattering analysis. ${ }^{\mathrm{d}}$ Polydispersity index $(\boldsymbol{\Xi})$ the particle size distribution.
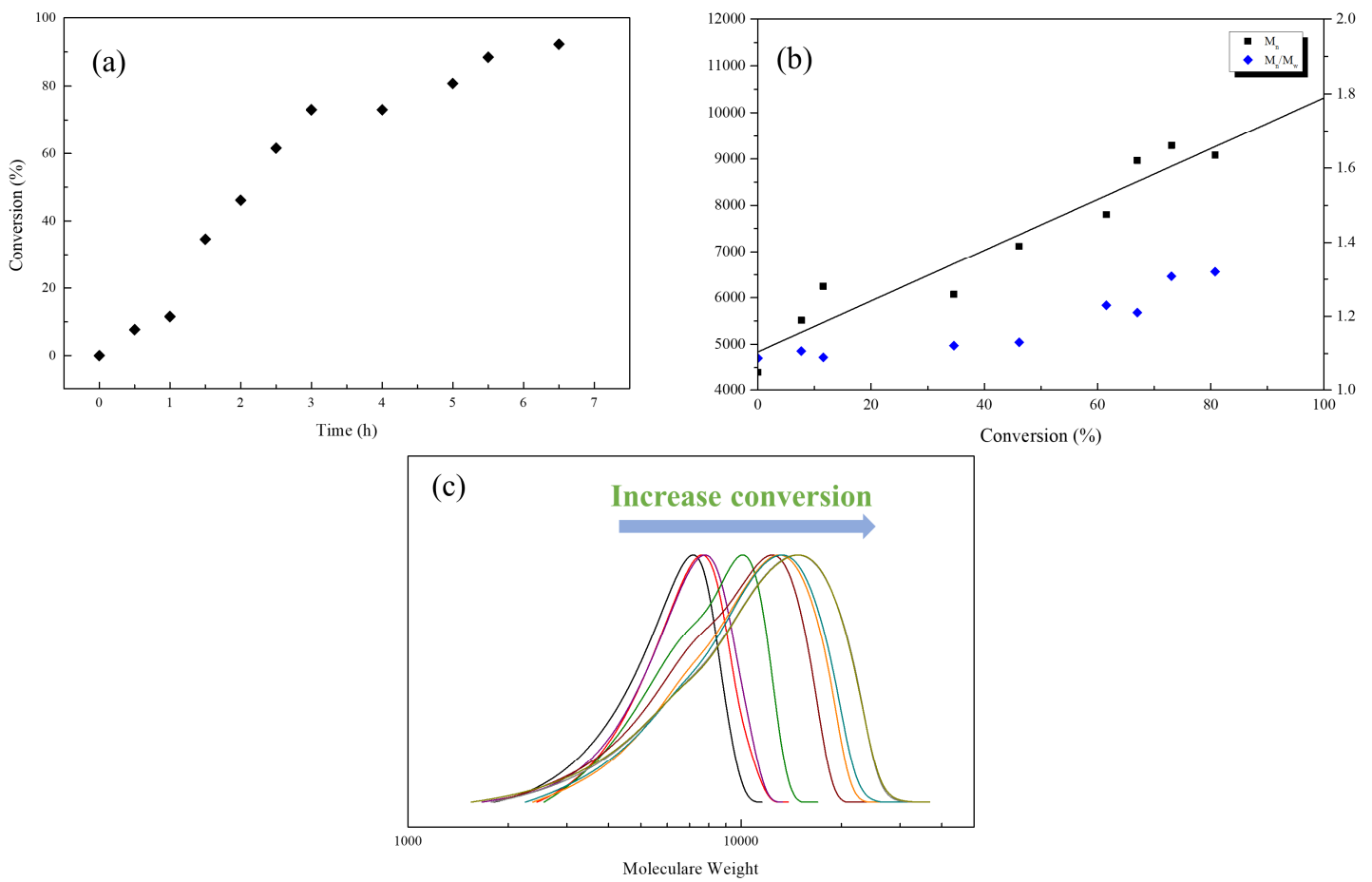

Figure 4. RAFT emulsion polymerization of DEVBP (B2) using poly (ethylene oxide)-based trithiocarbonate at $70{ }^{\circ} \mathrm{C}$ : (a) monomer conversion determined by ${ }^{1} \mathrm{H}$ NMR vs time, number average molar weight; (b) $M_{n}$, and polydispersity index, $M_{w} / M_{n}$, determined by GPC (polystyrene calibration) vs conversion; the straight line corresponds to the theoretical $M_{n}$ vs conversion (c) evolution of GPC with conversion. 

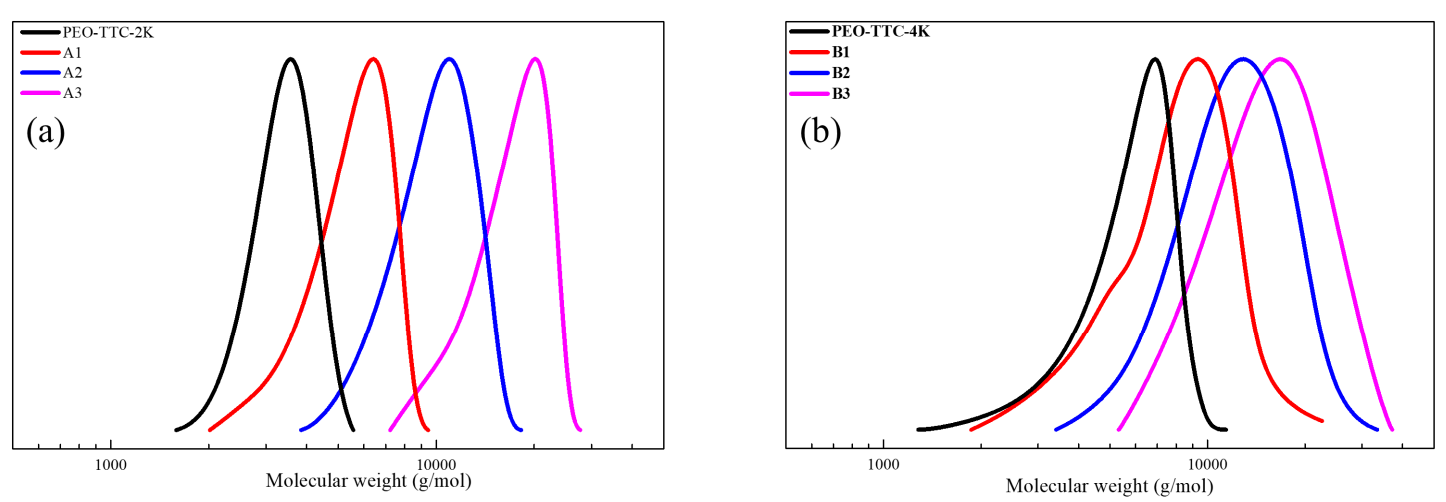

Figure 5. GPC trace of (a) PEG2k-b-PDVBP, (b) PEG4k-b-PDVBP.

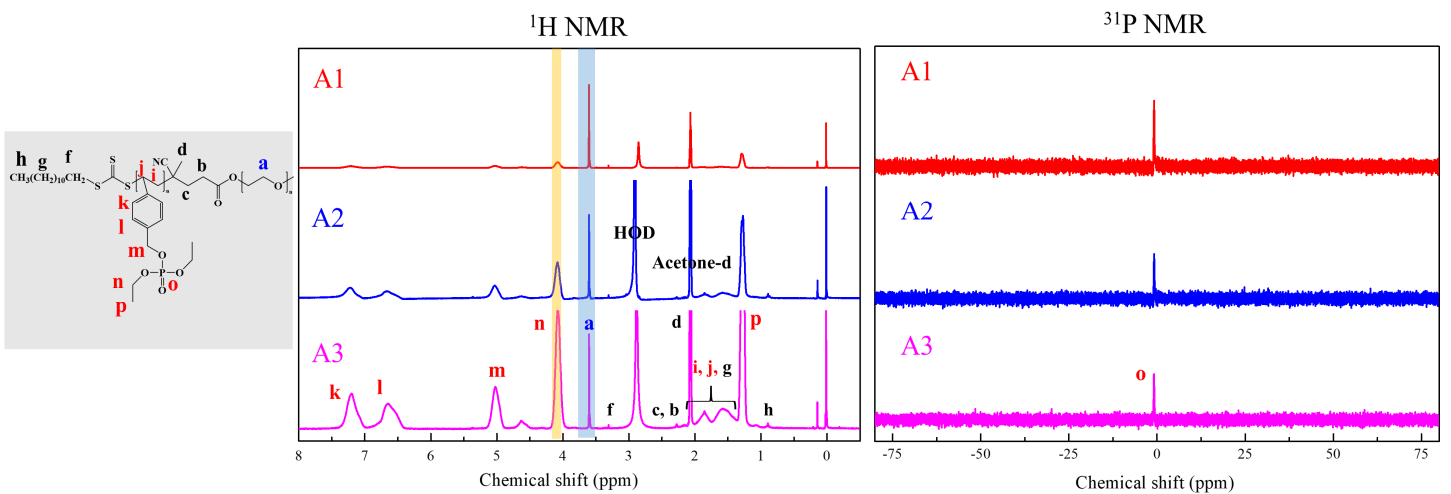

Figure 6. ${ }^{1} \mathrm{H}$ and ${ }^{31} \mathrm{P}$ NMR of PEG2k-b-PDVBP.

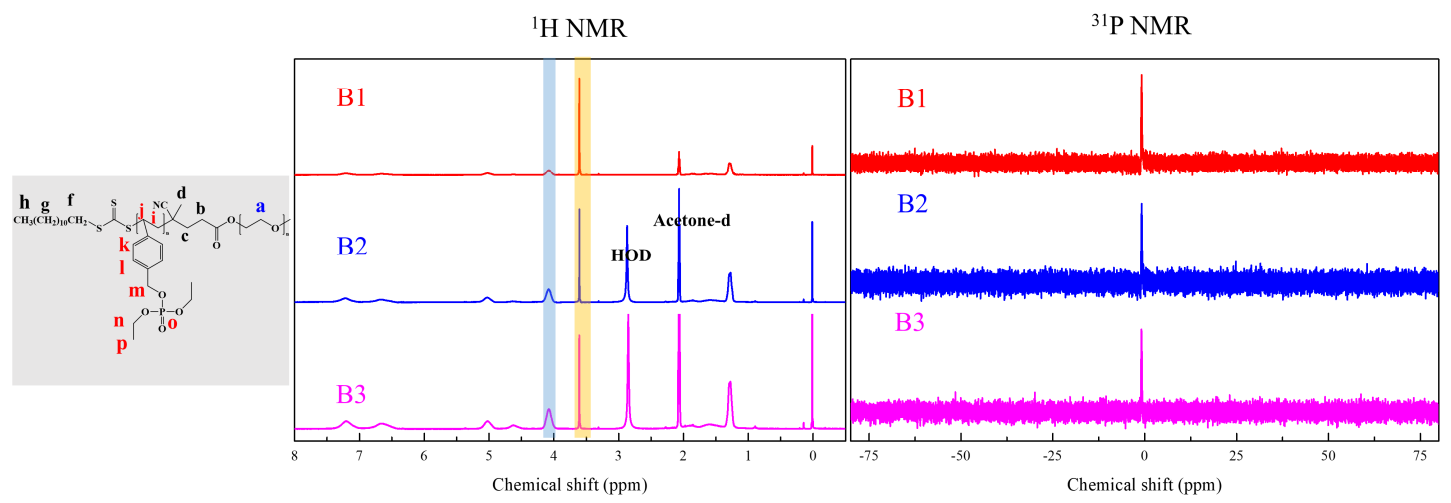

Figure 7. ${ }^{1} \mathrm{H}$ and ${ }^{31} \mathrm{P}$ NMR of PEG4k-b-PDVBP. 
A1
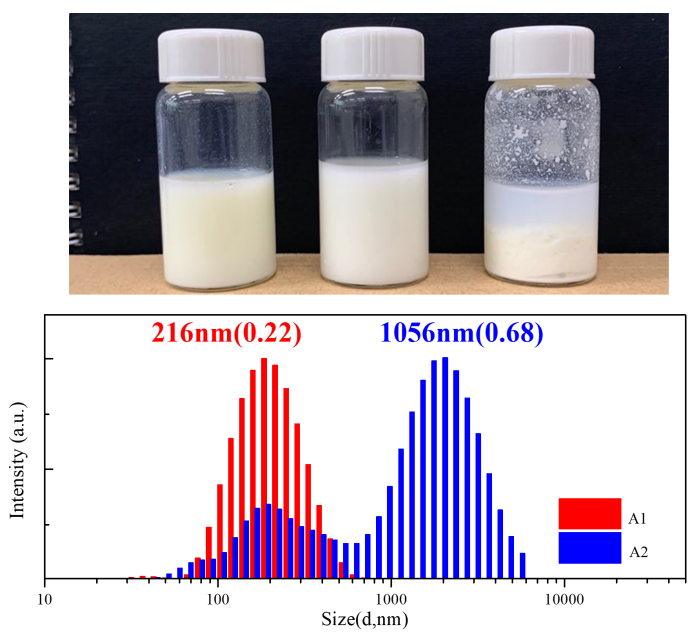

B1
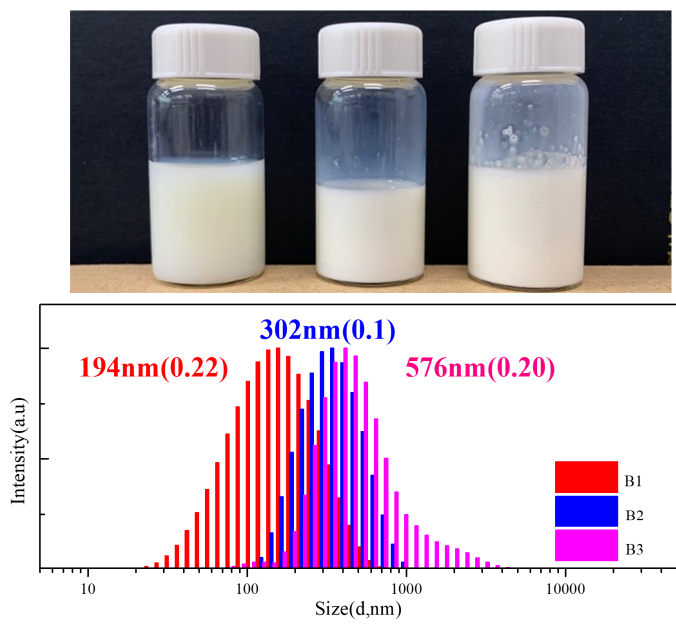

Figure 8. Emulsion polymerization and DLS measurements of PEG-b-PDVBP.

A1

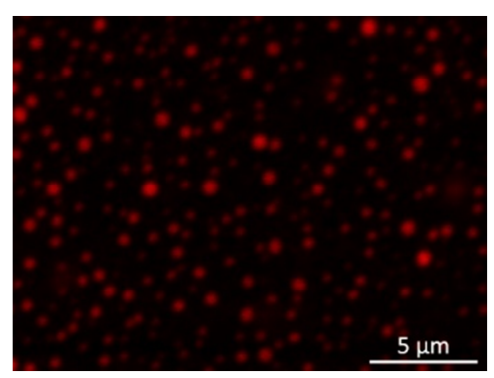

B1

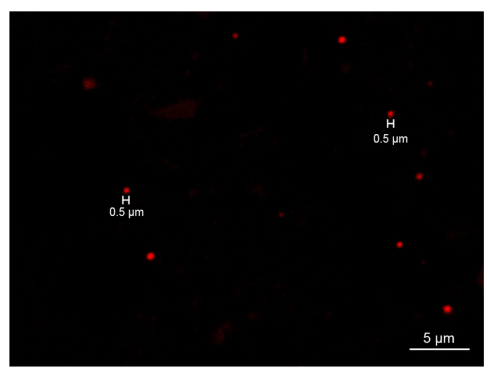

A2

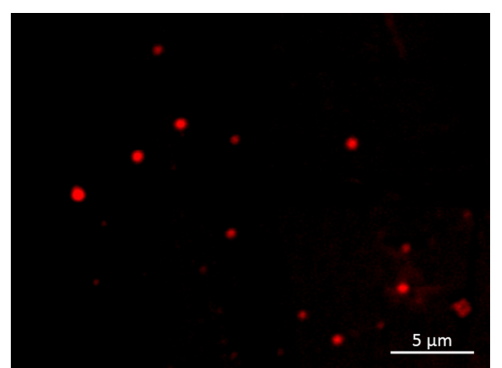

B2

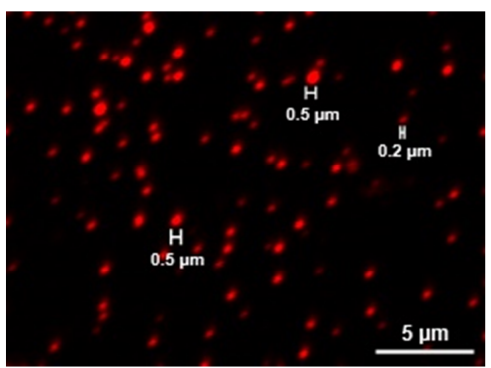

B3

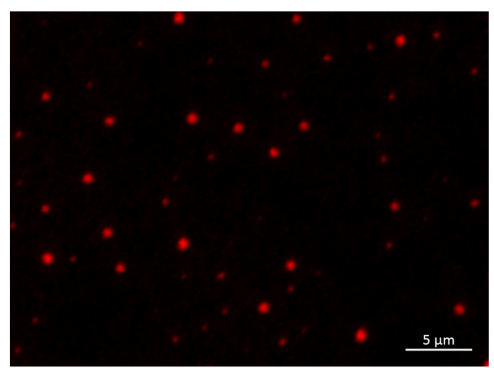

Figure 9. Confocal images of PEG-b-PDVBP submicron particles.

The flame retardant properties were analyzed by thermogravimetric analysis (TGA) with a heating rate of $10{ }^{\circ} \mathrm{C} / \mathrm{min}$ under air. The residual weight at $500{ }^{\circ} \mathrm{C}$, according to the weight percentage of phosphorus, was confirmed. The residual weight increased with increasing phosphorus weight percentage in PDVBP (Figure 10). PEG-TTC 2k, 4k and polystyrene mainly degraded at $380{ }^{\circ} \mathrm{C}$ and were degraded entirely at $400{ }^{\circ} \mathrm{C}$. The residue was $0 \%$ above $400{ }^{\circ} \mathrm{C}$. Different thermal degradation behaviors were observed in PDVBP. The thermal degradation of PDVBP (P contents: $9 \sim 10.2 \%$ ) started at 250 to $300{ }^{\circ} \mathrm{C}$; the residue weight was above $60 \%$. The initial degradation of PDVBP was contributed by the P-O-C structure functional group, $\mathrm{P}-\mathrm{O}-\mathrm{C}$ group of $-\mathrm{PO} 4$ is unstable than $-\mathrm{PO}_{1-3}$. Previously, $-\mathrm{PO}_{4}$ group was more effective for phosphorus release and forming char [22]. The second thermal degradation occurred at $400 \sim 430$ to $470{ }^{\circ} \mathrm{C}$, which was contributed by aromatic and PEG; the residue weights were $27.1 \sim 38.1 \%(\mathrm{~A} 1 \sim \mathrm{B} 3)$. Thermal degradation of aromatic group and PEG-TTC were occurred at high temperature (above $450{ }^{\circ} \mathrm{C}$ ) compared with polystyrene $\left(410{ }^{\circ} \mathrm{C}\right.$ ) and PEG-TTC $\left(380^{\circ} \mathrm{C}\right)$. It was evidenced to form char by phosphorus contents and PEG-b-PDEVBP submicron particles can provide flame retardant properties. After $500{ }^{\circ} \mathrm{C}$, the residue weights were 
constant. The residue weight was more than the P contents. Therefore, phosphorus can provide flame retardant properties. The thermal degradation behavior of PEG2k-b-PDVBP (A1 A3) differed slightly according to the $\mathrm{P}$ contents $(9.0 \sim 10.7)$. The final residue weight at $500{ }^{\circ} \mathrm{C}(27.1 \sim 37.8)$ and second thermal degradation temperature $\left(410 \sim 430{ }^{\circ} \mathrm{C}\right)$ increased with increasing $\mathrm{P}$ content. Although the thermal degradation behavior of PEG2k-b-PDVBP (B1 B3) differed according to the P content (7.6 $\sim 10.2)$, the residue weights were similar (24.5 38.1\%). Poly(vinyl alcohol) (PVA) is water soluble polymer and widely used for adhesive. To confirmed flame retardant properties of PEG-b-PDEVBP (B2) as an additive, TGA and micro combustion calorimetry were used as an instrument for assessing the flame retardancy of PEG-b-PDEVBP/PVA composite (Figure 11). PEG-b-PDEVBP submicron particles were added in PVA based on phosphorus contents $(0,3 \%, 5 \%)$, PVA was dissolved in water and added PEG-b-PDEVBP submicron particles. Thermal degradation of PVA were carried out in multi-step, first main thermal degradation was shown at $323^{\circ} \mathrm{C}$ and then the thermal degradation was complete at $550{ }^{\circ} \mathrm{C}$ (Figure 11a). In case of PVA/PEG-b-PDEVBP, initial thermal degradation temperature was decreased with PEG-b-PDEVBP contents but final thermal degradation temperature was increased (Figure 11a). There were a big difference of thermal degradation behavior between PVA and PVA/PEG-b-PDEVBP, thermal degradation behavior of PVA/PEG-b-PDEVBP according to phosphorous contents were a little. The inflection point of thermal initial decomposition temperature were slightly decreased with increasing phosphorous contents $\left(1 \% \rightarrow 3 \%, 272{ }^{\circ} \mathrm{C} \rightarrow 266^{\circ} \mathrm{C}\right)$. In the results of micro cone calorimeter (MCC) (Figure 11b), samples were heated at a rate of $1^{\circ} \mathrm{C} / \mathrm{min}$ from 100 to $750^{\circ} \mathrm{C}$. As the heat release rate (HRR) value, several overlapping peaks around the maximum value of $356{ }^{\circ} \mathrm{C}$ were observed. Overall HRR peaks of PVA/PEG-b-PDEVBP were distributed over a wider temperature range than PVA's one in Figure 11b. The initial temperature and value of HRR decreased, and the final temperature of HRR peaks increased by the increasing PEG-b-PDEVBP contents. It is indicated that phosphorus severs to delay heat dissipation and total heat release was also decreased by increasing PEG-b-PDEVBP. In results of MCC, THR and heat release time were significantly increased with phosphorous contents. Therefore, it was founded that PEG-b-PDEVBP could provide to give flame retardant property.
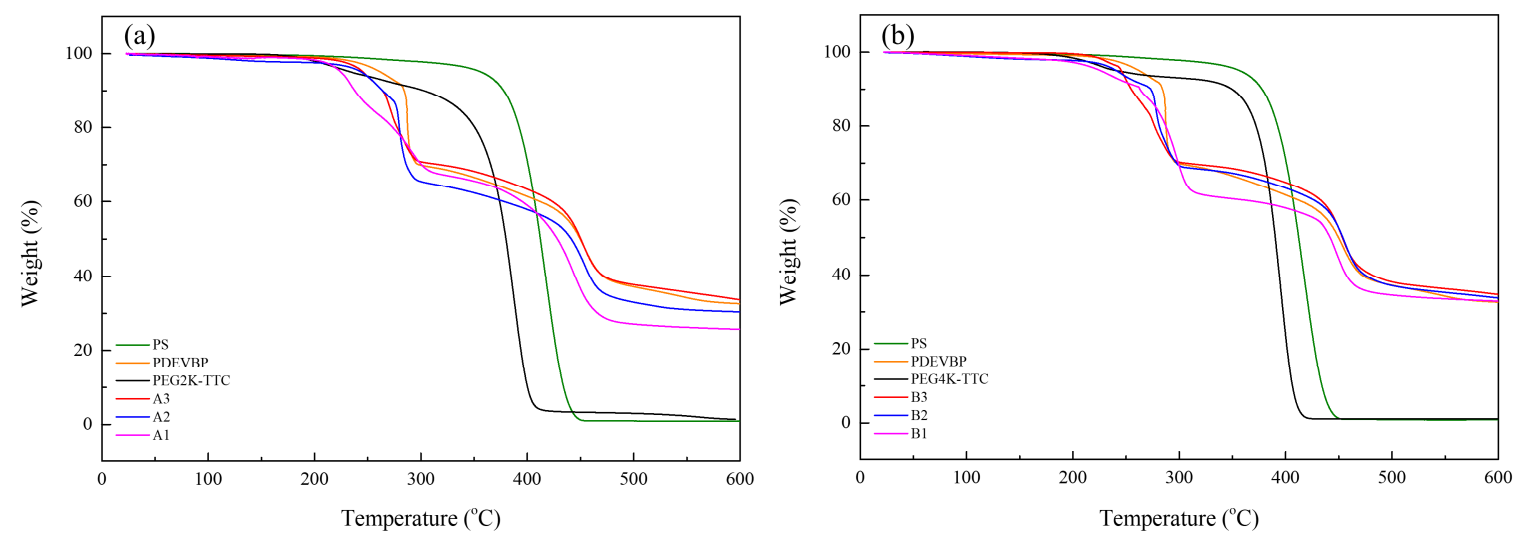

Figure 10. TGA measurements of (a) PEG2k-b-PDVBP, (b) PEG4k-b-PDVBP. 

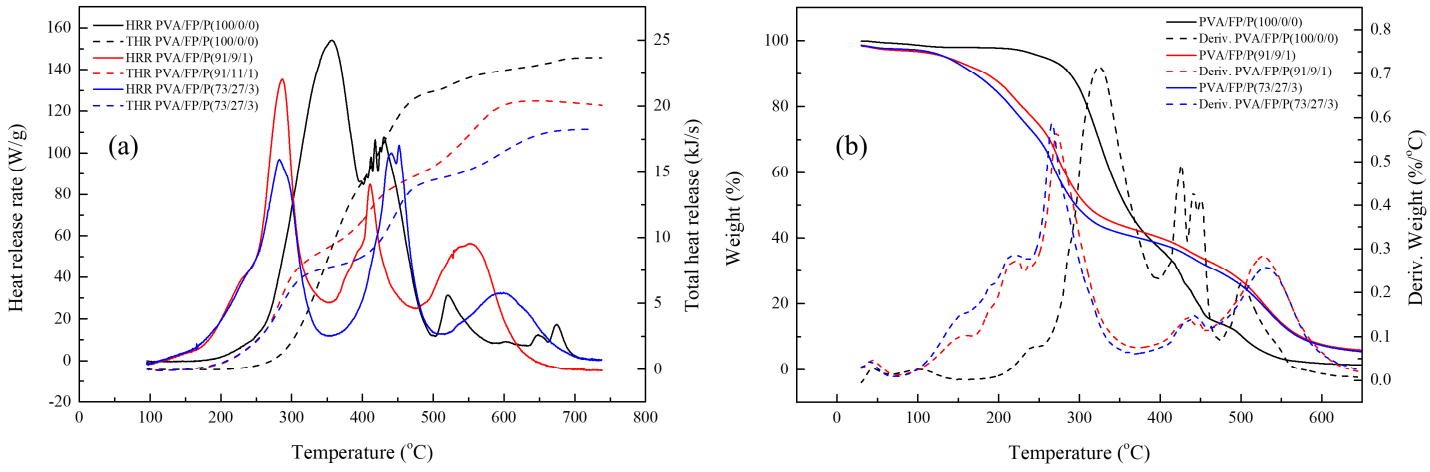

Figure 11. TGA measurements (a), Heat release rate (HRR) and total heat release (THR) (b) of PVA/PEG-b-PDEVBP; weight ratio of PVA/PEG-b-PDEVBP(FP, B2)/P (phosphorus contents) = PVA/FP/P.

\section{Conclusions}

The RAFT emulsion polymerization of DEVBP was conducted using a PEG-based amphiphilic RAFT agent. The well-defined PEG-b-PDVBP was obtained, and the behavior of RAFT emulsion polymerization for DEVBP was examined. PEG2k-PDVBP $\left(\mathrm{M}_{\mathrm{n}} / \mathrm{M}_{\mathrm{w}}: 1.07 \sim 1.08\right)$ showed a narrower molecular weight distribution than PEG4k-DEVBP $\left(\mathrm{M}_{\mathrm{n}} / \mathrm{M}_{\mathrm{w}}: 1.15 \sim 1.35\right)$. The z-average sizes of PEG2k-b-DEVBP were $216 \sim 1056 \mathrm{~nm}$ with a broad size distribution. A relatively short PEG2K chain was insufficient to stabilize PDEVBP block (above 65), on the other hand the submicron particles of PEG4k-b-DEVBP were obtained with relatively low particle size distribution than submicron particles of PEG2K-b-DEVBP. TGA and MCC were analyzed to examine the flame resident property of PEG-b-PDEVBP and PVA/PEG-b-PDEVBP as an additive. The residue weights of PEG-b-PDEVBP at $500{ }^{\circ} \mathrm{C}$ were $27.1 \sim 38.1 \%$ and thermal degradation temperature were also shift to high temperature in TGA measurements, which confirms that phosphorus contents provide flame retardant properties. The PEG4k-b-PDEVBP submicron particles were added in PVA and then flame retardant effect was confirmed by TGA and MCC analysis, thermal degradation temperature of PVA/PEG-b-PDEVBP increased. Moreover, HRR values were distributed over a wider temperature range and THR values decreased than PVA. Therefore, PEG-b-PDEVBP submicron particles can be assessed further as an additive for flame retardant organic and polymeric materials.

Author Contributions: Conceptualization, W.L., T.K. and H.-J.P., methodology, B.S., C.-S.L. and T.K., synthesis and characterization, J.-H.S. and J.-H.B.; writing-original draft preparation, T.K. and W.L.; writing-review and editing, T.K. and H.-J.P. All authors have read and agreed to the published version of the manuscript.

Funding: This research (No. SS2041-10; Development of Fine Chemical Material Thechnology for Industrial Leading) was funded by the Korea Research Institute of Chemical Technology (KRICT).

Conflicts of Interest: There are no conflicts to declare.

\section{References}

1. Monge, S.; David, G.; Ilia, A.; Ishihara, K.; Fontaine, L.; Allcock, H.R.; Wentrup-Byrne, E.; Moszner, N.; Cuesta, J.L.; Popa, A. Phosphorus-Based Polymers: From Synthesis to Applications; Royal Society of Chemistry: London, UK, 2014.

2. Zhang, Q.M.; Serpe, M.J. Synthesis, Characterization, and Antibacterial Properties of a Hydroxyapatite Adhesive Block Copolymer. Macromolecules 2014, 47, 8018-8025. [CrossRef]

3. Brunklaus, G.; Schauff, S.; Markova, D.; Klapper, M.; Müllen, K.; Spiess, H.-W. Proton Mobilities in Phosphonic Acid-Based Proton Exchange Membranes Probed by $1 \mathrm{H}$ and 2H Solid-State NMR Spectroscopy. J. Phys. Chem. B 2009, 113, 6674-6681. [CrossRef]

4. Quittmann, U.; Lecamp, L.; El Khatib, W.; Youssef, B.; Bunel, C. Synthesis of a New Phosphonated Dimethacrylate: Photocuring Kinetics in Homo- and Copolymerization, Determination of Thermal and Flame-Retardant Properties. Macromol. Chem. Phys. 2001, 202, 628-635. [CrossRef] 
5. Wang, H.; Niu, H.; Dong, J.-Y. Inherently flame retardant polypropylene copolymer. Polymer 2017, 126, 109-115. [CrossRef]

6. Canadell, J.; Hunt, B.J.; Cook, A.G.; Mantecón, A.; Cádiz, V. Flame retardance and shrinkage reduction of polystyrene modified with acrylate-containing phosphorus and crosslinkable spiro-orthoester moieties. Polym. Degrad. Stab. 2007, 92, 1482-1490. [CrossRef]

7. Wang, J.S.; Matyjaszewski, K. Controlled/"living" radical polymerization. atom transfer radical polymerization in the presence of transition-metal complexes. J. Am. Chem. Soc. 1995, 117, 5614-5615. [CrossRef]

8. Hawker, C.J.; Bosman, A.W.; Harth, E. New Polymer Synthesis by Nitroxide Mediated Living Radical Polymerizations. Chem. Rev. 2001, 101, 3661-3688. [CrossRef]

9. Perrier, S. 50th Anniversary Perspective: RAFT Polymerization-A User Guide. Macromolecules 2017, 50, 7433-7447. [CrossRef]

10. Kim, T.; Mays, J.; Chung, I. Porous poly( $\varepsilon$-caprolactone) microspheres via UV photodegradation of block copolymers prepared by RAFT polymerization. Polymer 2018, 158, 198-203. [CrossRef]

11. McLeary, J.B.; Klumperman, B. RAFT mediated polymerisation in heterogeneous media. Soft Matter 2006, 2, 45-53. [CrossRef]

12. Zhou, J.; Yao, H.; Ma, J. Recent advances in RAFT-mediated surfactant-free emulsion polymerization. Polym. Chem. 2018, 9, 2532-2561. [CrossRef]

13. Truong, N.P.; Quinn, J.F.; Anastasaki, A.; Rolland, M.; Vu, M.N.; Haddleton, D.M.; Whittaker, M.R.; Davis, T.P. Surfactant-free RAFT emulsion polymerization using a novel biocompatible thermoresponsive polymer. Polym. Chem. 2017, 8, 1353-1363. [CrossRef]

14. Khor, S.Y.; Vu, M.N.; Pilkington, E.H.; Johnston, A.P.R.; Whittaker, M.R.; Quinn, J.F.; Truong, N.P.; Davis, T.P. Elucidating the Influences of Size, Surface Chemistry, and Dynamic Flow on Cellular Association of Nanoparticles Made by Polymerization-Induced Self-Assembly. Small 2018, 14, 1801702. [CrossRef]

15. Huang, J.; Matyjaszewski, K. Atom Transfer Radical Polymerization of Dimethyl(1-ethoxycarbonyl)vinyl Phosphate and Corresponding Block Copolymers. Macromolecules 2005, 38, 3577-3583. [CrossRef]

16. Mukumoto, K.; Zhong, M.; Matyjaszewski, K. Atom transfer radical polymerization of dimethyl(methacryloyloxymethyl) phosphonate. Eur. Polym. J. 2014, 56, 11-16. [CrossRef]

17. Britze, A.; Moosmann, K.; Jähne, E.; Adler, H.-J.; Kuckling, D. Synthesis of Block Copolymers Modified with Phosphonate Ester Groups Using Nitroxide-Mediated Radical Polymerization. Macromol. Rapid Commun. 2006, 27, 1906-1912. [CrossRef]

18. Hanisch, A.; Yang, P.; Kulak, A.N.; Fielding, L.A.; Meldrum, F.C.; Armes, S.P. Phosphonic Acid-Functionalized Diblock Copolymer Nano-Objects via Polymerization-Induced Self-Assembly: Synthesis, Characterization, and Occlusion into Calcite Crystals. Macromolecules 2016, 49, 192-204. [CrossRef]

19. Canniccioni, B.; Monge, S.; David, G.; Robin, J.-J. RAFT polymerization of dimethyl(methacryloyloxy)methyl phosphonate and its phosphonic acid derivative: A new opportunity for phosphorus-based materials. Polym. Chem. 2013, 4, 3676-3685. [CrossRef]

20. Furukawa, J.; Kobayashi, E.; Wakui, T. Phosphorus-Containing Polystyrene Derivatives as Flame Resistance. Polym. J. 1980, 12, 277-285. [CrossRef]

21. Dumitrascu, A.; Howell, B.A. Flame-retarding vinyl polymers using phosphorus-functionalized styrene monomers. Polym. Degrad. Stab. 2011, 96, 342-349. [CrossRef]

22. Schartel, B. Phosphorus-based Flame Retardancy Mechanisms-Old Hat or a Starting Point for Future Development? Materials (Basel) 2010, 3, 4710-4745. [CrossRef] [PubMed]

23. Schartel, B.; Balabanovich, A.I.; Braun, U.; Knoll, U.; Artner, J.; Ciesielski, M.; Döring, M.; Perez, R.; Sandler, J.K.W.; Altstädt, V.; et al. Pyrolysis of epoxy resins and fire behavior of epoxy resin composites flame-retarded with 9,10-dihydro-9-oxa-10-phosphaphenanthrene-10-oxide additives. J. Appl. Polym. Sci. 2007, 104, 2260-2269. [CrossRef]

24. Moad, G.; Rizzardo, E.; Thang, S.H. Living Radical Polymerization by the RAFT Process. Aust. J. Chem. 2005, 58, 379. [CrossRef]

25. Zheng, X.; Wilkie, C.A. Flame retardancy of polystyrene nanocomposites based on an oligomeric organically-modified clay containing phosphate. Polym. Degrad. Stab. 2003, 81, 539-550. [CrossRef] 
26. Rieger, J.; Stoffelbach, F.; Bui, C.; Alaimo, D.; Jérôme, C.; Charleux, B. Amphiphilic Poly(ethylene oxide) Macromolecular RAFT Agent as a Stabilizer and Control Agent in ab Initio Batch Emulsion Polymerization. Macromolecules 2008, 41, 4065-4068. [CrossRef]

27. dos Santos, A.M.; Pohn, J.; Lansalot, M.; D'Agosto, F. Combining Steric and Electrostatic Stabilization Using Hydrophilic MacroRAFT Agents in an Ab Initio Emulsion Polymerization of Styrene. Macromol. Rapid Commun. 2007, 28, 1325-1332. [CrossRef]

28. Rieger, J.; Osterwinter, G.; Bui, C.; Stoffelbach, F.; Charleux, B. Surfactant-Free Controlled/Living Radical Emulsion (Co)polymerization of n-Butyl Acrylate and Methyl Methacrylate via RAFT Using Amphiphilic Poly(ethylene oxide)-Based Trithiocarbonate Chain Transfer Agents. Macromolecules 2009, 42, 5518-5525. [CrossRef]

29. Truong, N.P.; Dussert, M.V.; Whittaker, M.R.; Quinn, J.F.; Davis, T.P. Rapid synthesis of ultrahigh molecular weight and low polydispersity polystyrene diblock copolymers by RAFT-mediated emulsion polymerization. Polym. Chem. 2015, 6, 3865-3874. [CrossRef]

(C) 2020 by the authors. Licensee MDPI, Basel, Switzerland. This article is an open access article distributed under the terms and conditions of the Creative Commons Attribution (CC BY) license (http://creativecommons.org/licenses/by/4.0/). 